\title{
GPS measurements of present-day uplift in the Southern Tibet
}

\author{
Caijun Xu, Jingnan Liu, Chenghua Song, Weiping Jiang, and Chuang Shi \\ School of Geoscience and Surveying Engineering, Wuhan Technical University of Surveying and Mapping (WTUSM), \\ 129 Luyou Road, Wuhan 430079, P. R. China
}

(Received December 31, 1999; Revised May 17, 2000; Accepted May 19, 2000)

\begin{abstract}
Wuhan Technical University Surveying and Mapping (WTUSM) carried out three GPS campaigns in the Tibetan Plateau since 1993. To improve the vertical component precision of GPS measurement, we estimated the remaining tropospheric refraction using the piecewise linear method after the SAASTAMOINEN model and corrected the tropospheric refraction by selecting one parameter for every two hours model to consider the variation of tropospheric refraction. Using the IGS combined ephemeris and corresponding EOP Series for 1995 and 1997 GPS campaigns, all baseline vectors were processed by GAMIT (Ver. 9.71) software, and network adjustment was carried out in ITRF97 frame by PowerAdj software (Ver. 3.3) which was developed by WTUSM considering the baseline vectors' full covariance matrix. The resulting vertical velocity field determined from GPS campaigns in 1995 and 1997 shows that the average uplift rate in ITRF 97 frame is about $7.8 \pm 7.6 \mathrm{~mm} / \mathrm{yr}$ for all 14 repeated surveying stations in Tibet, and the average uplift rate is $16.2 \pm 7.9 \mathrm{~mm} / \mathrm{yr}$ in southern Tibet, which are compared with the results from the gravity measurements, leveling data and fission-track dating (FT).
\end{abstract}

\section{Introduction}

The high elevation of the Himalayas and Tibet is resulted from the continuing collision between India and Asia, which started more than $45 \sim 50$ million years ago (Ma et al., 1998). Leveling data with very sparse spatial sampling in southern Tibet between 1959 and 1981 suggest that the Himalayan divide may be rising at a rate of $7.5 \pm 5.6 \mathrm{~mm} / \mathrm{yr}$ relative to central Tibet (Jackson and Bilham, 1994a, b). First-order precise leveling data in Tibet from Geolmud to Lhasa, and from Shiqianhe to Lhasa between 1959 to 1961 and 1979 to 1981 suggest that Tibet vises at rate of $5.8 \mathrm{~mm} / \mathrm{yr}$ relative to Xining (Zhang, 1991). Leveling data also suggest the southern Tibet rising at rate more than $10 \mathrm{~mm} / \mathrm{yr}$ (Zhang, 1987; Jiang, 1989; Zhang, 1991; Ma, 1989; Wang et al., 1993; Chen, 1996). FT (Fission-track dating) result shows an average uplift rate between $10 \mathrm{~mm} / \mathrm{yr}$ to $30 \mathrm{~mm} / \mathrm{yr}$ in Himalayas since $1 \mathrm{Ma}$ (Zhong and Ding, 1996).

Although the vertical component uncertainty in GPS measurements is longer than $5 \mathrm{~mm}$, vertical movements can be measured in areas where the uplift rate is high. Three GPS campaigns were carried out in the Tibetan plateau by WTUSM in 1993, 1995 and 1997. Since there was no IGS combined ephemeris and corresponding EOP Series for 1993 GPS campaign, we studied the uplift rate in southern Tibet using GPS measurements in 1995 and 1997 in this paper.

\section{GPS Campaigns}

A sketch of GPS monitoring sites in the Qinghai-Tibet plateau is shown in Fig. 1. The GPS Monitoring sites are mainly deployed in the Tibet block, Himalayan block, and

Copy right(c) The Society of Geomagnetism and Earth, Planetary and Space Sciences (SGEPSS); The Seismological Society of Japan; The Volcanological Society of Japan; The Geodetic Society of Japan; The Japanese Society for Planetary Sciences.
Qaidam block. The GPS-chain network crosses the HonxilBayan Har, Jinsha Jiang, Nujiang-Lancang Jiang and Yarlung Zangbo Jiang rift systems. The shortest baseline and longest baseline in the network are $62 \mathrm{~km}$ and $1185 \mathrm{~km}$ respectively, the mean length of baselines is $364 \mathrm{~km}$. The first GPS campaign took place from July 18 to August 24, 1993, the second one took place from June 5 to July 5,1995 , and the third one carried out from June 5 to June 25, 1997. There were two observation sessions at every site in each campaign, one was in daytime, the other was at night, and every observation session lasted 9 hours. The details of the GPS campaigns are listed in Table 1.

\section{GPS Data Processing}

We used the GAMIT software (King and Bock, 1995) to estimate daily station positions simultaneously with orbital and atmospheric parameters using dual-frequency, doubly differenced GPS phase observations at sites in Tibet and Lhasa IGS station. We use the GLOBK software (Herring, 1995) to combine the daily solutions of each survey. Both orbital and station parameters are estimated, allowing orbital parameters to vary stochastically according to the level of unmodeled accelerations of the satellites and the strength of the global tracking data. The final solution file contains (loosely constrained) estimates of station positions for each (few-day to several-week) survey, with orbital parameters suppressed. We use the PowerAdj software Ver. 3.3, which is developed by WTUSM, to combine the solution files ("quasiobservations") from all of the surveys in order to estimate station positions and their velocities.

\subsection{Fiducial station and GPS precise ephemeris}

The Fiducial point technique has been used in data processing. Lhasa station was chosen as the fiducial station. Using its ITRF97 coordinates and velocity, the station coordinate 


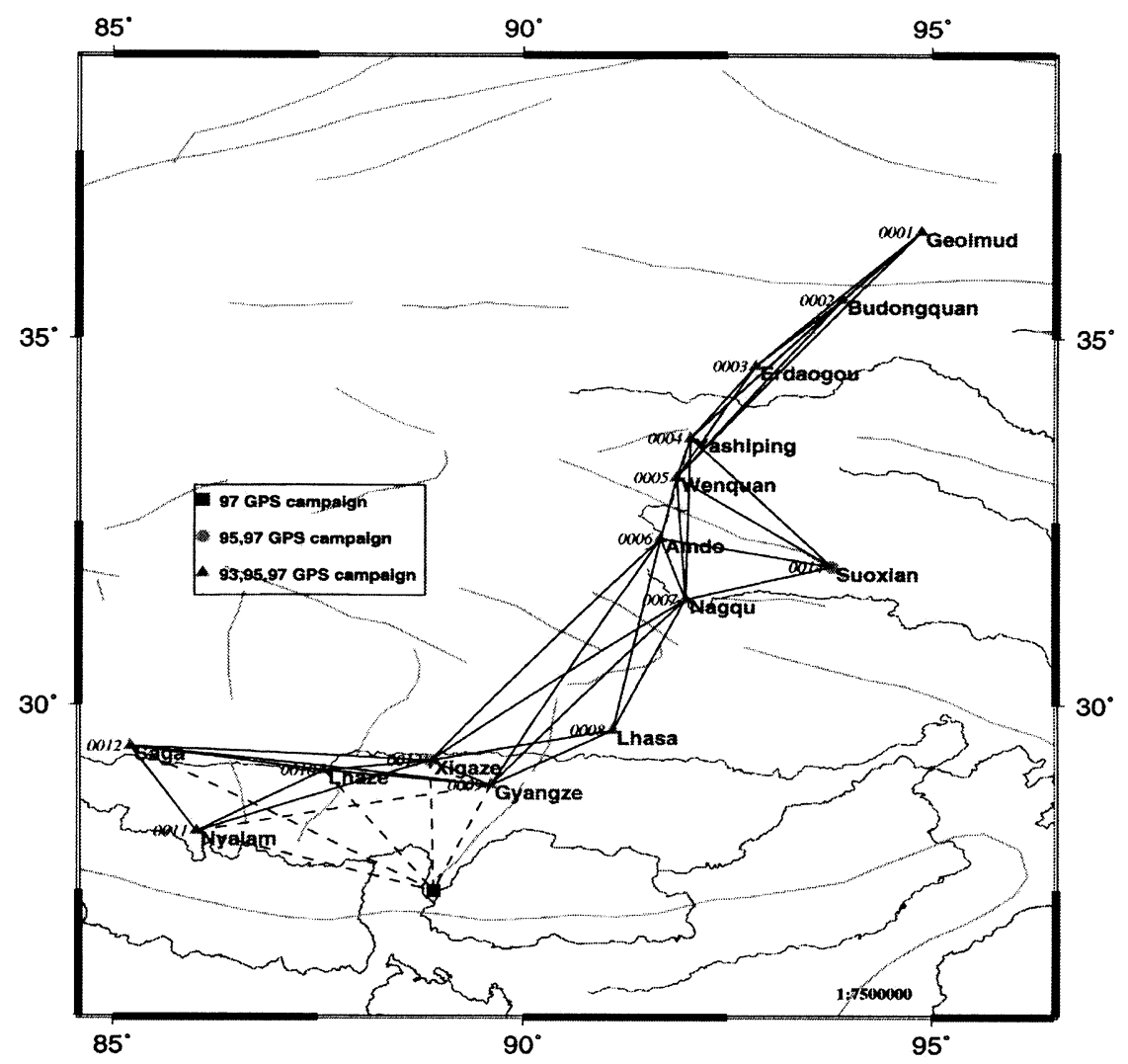

Fig. 1. Sketch of GPS monitoring sites in the Qinghai-Tibet plateau.

Table 1. Statistics for GPS campaigns in Tibet plateau.

\begin{tabular}{|c|c|c|c|c|c|c|c|c|}
\hline \multirow{2}{*}{$\begin{array}{l}\text { Camp. } \\
\text { period }\end{array}$} & \multirow{2}{*}{$\begin{array}{c}\text { Monitoring } \\
\text { stations }\end{array}$} & \multicolumn{5}{|c|}{ Synchronous observation } & \multicolumn{2}{|c|}{ Receiver } \\
\hline & & total & 2 sites & 3 sites & 4 sites & 5 sites & type & number \\
\hline 1993. 7-8 & 13 & 18 & 3 & 15 & 0 & 0 & Rogue SNR 8000 & 3 \\
\hline 1995. 6-7 & 15 & 16 & 0 & 4 & 12 & 0 & Rogue SNR 8000 & 4 \\
\hline 1997. 6 & 15 & 12 & 0 & 1 & 1 & 10 & Rogue SNR 8000 & 5 \\
\hline
\end{tabular}

was reduced to the observation instantaneous epoch corresponding to the ephemeris. In each solution the coordinates were assigned a priori constraint of $5 \mathrm{~mm}$ for horizontal and $10 \mathrm{~mm}$ for vertical. We used the IGS combined ephemeris and corresponding EOP Series for 1995 and 1997 GPS campaigns. The satellite coordinates were constrained within a priori uncertainty of $0.01 \sim 0.1 \mathrm{ppm}$.

\subsection{Tropospheric correction}

The tropospheric refraction is the main limiting factor in GPS positioning, especially there is exquiste variation of weather in Tibetan Plateau. The RMS of vertical component will be improved if the influence of tropospheric refraction is reduced. In data processing we estimated the remaining tropospheric refraction using the piecewise linear method after the SAASTAMOINEN model corrected the tropospheric refraction. Choosing tropospheric delay bias parameters are critical for fitting the tropospheric refraction and getting good results. RMS of GPS site coordinates is shown in Table 2(a) for 5 kinds of testing situation. Situation $\mathrm{c}$ is the best method for improving the daily solution considering synthetically the results (repeatability of baseline components) in Table 2(a), so we select one parameter every two hours after the SAASTAMOINEN model for tropospheric correcting.

\subsection{Repeatability of baseline}

Repeatability of baseline's component can express the precision of solution, and is one of the most important quality indexes of GPS positioning. Repeatability (daily to daily solution over the weighted mean square error) $\sigma$ can be expressed with fixed error and scale error. It may be described as follows:

$$
\sigma=a+b l
$$

Here $a$ is fixed error and $b$ is scale error, $l$ is length of each component repeatability of baseline component is listed in Table 2(b). Table 2(b) shows that repeatability of vertical component is better than $6.4 \mathrm{~mm}+0.17 \times 10^{-8} \times l$.

3.4 Adjustment of each campaigns in an uniform datum

PowerADJ Ver. 3.3 developed by WTUSM is used to process the baseline vectors including their full covariance ma- 
Table 2(a). Comparison of Repeatability of baseline component.

\begin{tabular}{ccccc}
\hline & N-S & E-W & UP & L \\
& $a+b \times 10^{-8} l$ & $a+b \times 10^{-8} l$ & $a+b \times 10^{-8} l$ & $a+b \times 10^{-8} l$ \\
\hline a & $0.3 \mathrm{~mm}+0.95 \times 10^{-8} l$ & $2.5 \mathrm{~mm}+0.19 \times 10^{-8} l$ & $5.5 \mathrm{~mm}+1.12 \times 10^{-8} l$ & $0.6 \mathrm{~mm}+1.04 \times 10^{-8} l$ \\
b & $0.6 \mathrm{~mm}+0.70 \times 10^{-8} l$ & $2.1 \mathrm{~mm}+0.17 \times 10^{-8} l$ & $5.0 \mathrm{~mm}+1.42 \times 10^{-8} l$ & $0.8 \mathrm{~mm}+0.74 \times 10^{-8} l$ \\
c & $0.4 \mathrm{~mm}+0.91 \times 10^{-8} l$ & $1.3 \mathrm{~mm}+0.12 \times 10^{-8} l$ & $5.4 \mathrm{~mm}+1.36 \times 10^{-8} l$ & $0.3 \mathrm{~mm}+0.95 \times 10^{-8} l$ \\
d & $0.6 \mathrm{~mm}+0.92 \times 10^{-8} l$ & $2.2 \mathrm{~mm}+0.17 \times 10^{-8} l$ & $6.9 \mathrm{~mm}+1.42 \times 10^{-8} l$ & $0.5 \mathrm{~mm}+0.74 \times 10^{-8} l$ \\
e & $0.4 \mathrm{~mm}+1.1 \times 10^{-8} l$ & $2.2 \mathrm{~mm}+0.13 \times 10^{-8} l$ & $6.1 \mathrm{~mm}+2.21 \times 10^{-8} l$ & $0.7 \mathrm{~mm}+0.70 \times 10^{-8} l$ \\
\hline
\end{tabular}

a-one parameter every half hour for modeling the variation of the tropospheric refraction, $b$ - one parameter every one hour for modeling the variation of the tropospheric refraction, c-one parameter every two hours for modeling the variation of the tropospheric refraction, $\mathrm{d}-$ one parameter every four hours for modeling the variation of the tropospheric refraction, e-one parameter for modeling the variation of the tropospheric refraction.

Table 2(b). Comparison of Repeatability of baseline component.

\begin{tabular}{ccccc}
\hline & N-S & E-W & UP & L \\
& $a+b \times 10^{-8} l$ & $a+b \times 10^{-8} l$ & $a+b \times 10^{-8} l$ & $a+b \times 10^{-8} l$ \\
\hline 95 & $2.3 \mathrm{~mm}+0.02 \times 10^{-8} l$ & $5.8 \mathrm{~mm}+0.64 \times 10^{-8} l$ & $6.2 \mathrm{~mm}+0.17 \times 10^{-8} l$ & $4.2 \mathrm{~mm}+0.15 \times 10^{-8} l$ \\
97 & $2.9 \mathrm{~mm}+0.05 \times 10^{-8} l$ & $2.4 \mathrm{~mm}+0.08 \times 10^{-8} l$ & $6.4 \mathrm{~mm}+0.17 \times 10^{-8} l$ & $2.0 \mathrm{~mm}+0.25 \times 10^{-8} l$ \\
\hline
\end{tabular}

Table 3. Data information of GPS campaigns in adjustment.

\begin{tabular}{|c|c|c|c|c|}
\hline \multicolumn{3}{|c|}{ Datum of daily solution } & \multicolumn{2}{|c|}{$\begin{array}{l}\text { Adjustment datum for } \\
\text { GPS campaigns }\end{array}$} \\
\hline $\begin{array}{l}\text { Precise ephemeris } \\
\text { and EOP }\end{array}$ & $\begin{array}{l}\text { Reference frame of ephemeris } \\
\text { and fiducial station }\end{array}$ & $\begin{array}{c}\text { Observation } \\
\text { instantaneous epoch }\end{array}$ & $\begin{array}{l}\text { Reference frame of } \\
\text { fiducial stations }\end{array}$ & Epoch \\
\hline IGS & ITRF93 & 1995.47 & ITRF97 & 1995.47 \\
\hline IGS & ITRF94 & 1997.46 & ITRF97 & 1997.46 \\
\hline
\end{tabular}

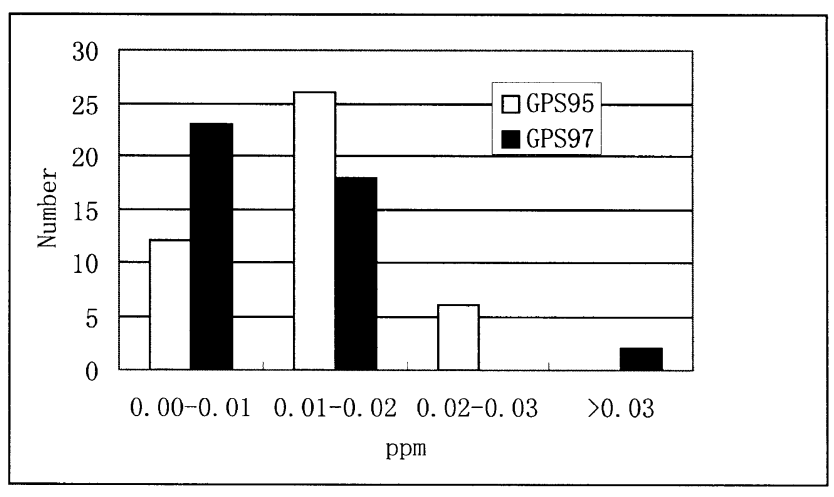

Fig. 2(a). Statistics for precision of GPS baselines (RMS ratio to baseline length).

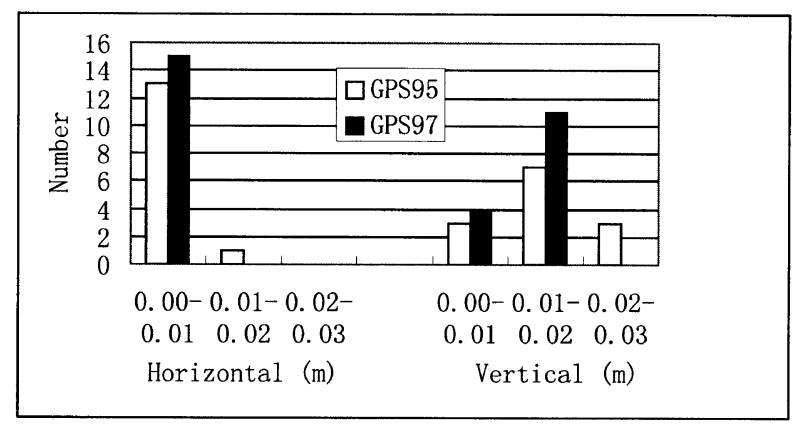

Fig. 2(b). Statistics for precision of GPS site coordinates (RMS). trix. The data information of GPS campaigns in the adjustment is listed in Table 3. Statistics for RMS ratio to baseline length and RMS of GPS site coordinates are shown in Fig. 2(a) and (b), respectively.

\section{Uplifting Rate in Tibet}

The following characteristics of vertical deformation in Tibet are derived from our solutions listed in Table 4 and Fig. 3. 
Table 4. Vertical motion rate in Tibet by GPS campaigns in 1995 and 1997 in ITRF97 frame.

\begin{tabular}{|c|c|c|c|c|c|}
\hline Site & $\begin{array}{c}\text { Longitude } \\
\text { East }\left({ }^{\circ}\right)\end{array}$ & $\begin{array}{l}\text { Latitude } \\
\text { North }\left(^{\circ}\right)\end{array}$ & $\begin{array}{c}\text { Uplifting rate } \\
\mathrm{mm} / \mathrm{yr}\end{array}$ & $\begin{array}{l}\text { RMS } \\
\mathrm{mm} / \mathrm{yr}\end{array}$ & remark \\
\hline $\begin{array}{l}\text { Geolmud (GL) } \\
(0001)\end{array}$ & 94.9 & 36.4 & 5.0 & 9.5 & \\
\hline $\begin{array}{c}\text { Budongqua (BD) } \\
(0002)\end{array}$ & 93.9 & 35.5 & 1.1 & 9.5 & \\
\hline $\begin{array}{c}\text { Erdaogou (ED) } \\
\quad(0003)\end{array}$ & 92.8 & 34.6 & 8.9 & 9.1 & \\
\hline $\begin{array}{c}\text { Yanshiping (YS) } \\
(0004)\end{array}$ & 92.0 & 33.6 & 6.4 & 8.9 & \\
\hline $\begin{array}{c}\text { Wenquan (WQ) } \\
(0005)\end{array}$ & 91.9 & 33.1 & -10.4 & 7.9 & \\
\hline $\begin{array}{l}\text { Amdo (AD) } \\
\quad(0006)\end{array}$ & 91.7 & 32.3 & 9.8 & 6.6 & \\
\hline $\begin{array}{c}\text { Suoxian (SX) } \\
(0014)\end{array}$ & 93.8 & 31.9 & 6.6 & 7.9 & \\
\hline $\begin{array}{l}\text { Naque (NQ) } \\
\quad(0007)\end{array}$ & 92.0 & 31.4 & 7.8 & 6.0 & \\
\hline $\begin{array}{l}\text { Lhasa (LS) } \\
\quad(0008)\end{array}$ & 91.1 & 29.7 & 2.3 & 1.0 & \\
\hline $\begin{array}{l}\text { Saga (SG) } \\
\quad(0012)\end{array}$ & 85.2 & 29.4 & 7.0 & 4.4 & \\
\hline $\begin{array}{l}\text { Xigaze }(\mathrm{XG}) \\
(0013)\end{array}$ & 88.9 & 29.2 & 6.6 & 6.6 & in Southern Tibe \\
\hline $\begin{array}{l}\text { Lhaze (LZ) } \\
\quad(0010)\end{array}$ & 87.6 & 29.1 & 19.2 & 7.2 & in Southern Tibe \\
\hline $\begin{array}{c}\text { Gyangze (GZ) } \\
(0009)\end{array}$ & 89.6 & 28.9 & 17.0 & 6.1 & in Southern Tibe \\
\hline $\begin{array}{c}\text { Nyalam (NL) } \\
(0011)\end{array}$ & 86.0 & 28.3 & 22.1 & 7.4 & in Southern Tibe \\
\hline
\end{tabular}

(1) In southern Tibet (NL, GZ, LZ, XG), the vertical motion rate is between $6.6 \pm 6.6 \mathrm{~mm} / \mathrm{yr}$ to $22.1 \pm 7.4 \mathrm{~mm} / \mathrm{yr}$, and the average vertical motion rate is $16.2 \pm 7.9 \mathrm{~mm} / \mathrm{yr}$ in ITRF97 frame.

(2) The average vertical motion rate is $7.8 \pm 7.6 \mathrm{~mm} / \mathrm{yr}$ for the 14 repeated surveying stations in Tibet by GPS campaigns 95 and 97 in ITRF97 frame.

The uplifting rates in Southern Tibet obtained by GPS measurements are agree with $7.5 \pm 5.6 \mathrm{~mm} / \mathrm{yr}$ relative to central Tibet from regional leveling data (Jackson and Bilham, 1994a, b) and more than $10 \mathrm{~mm} / \mathrm{yr}$ in Southern Tibet estimated from leveling data relative to Huanghai mean sea level (Zhang, 1987; Zhang, 1991). They are also consistent with uplifting rate of $11.98 \mathrm{~mm} / \mathrm{yr}$ relative to ChengDu, Sichuan province, calculated from gravity measurements (Zhang, 1996) and rates between $10 \mathrm{~mm} / \mathrm{yr}$ to $30 \mathrm{~mm} / \mathrm{yr}$ in Himalayan terrain since $1 \mathrm{Ma}$ inferred fission-track dating (FT) and its sampling heights of rocks (Zhong and Ding, 1996).

\section{Discussions and Conclusions}

The average uplift rate is about $16.2 \pm 7.9 \mathrm{~mm} / \mathrm{yr}$ in the Southern Tibet estimated by GPS95 and GPS97 measurements in ITRF97 frame, which agree with the rates obtained from leveling data, gravity data and Fission-track dating (FT). The agreement of present-day GPS providing rate and geological mean rate from FT shows that the Cenozoic tectonic activity is still very active in the Southern Tibet and its surrounding regions. It is possible to determine vertical motion rate by GPS measurements in the Southern Tibet. The precision of vertical component of GPS measurements can be improved by adopting a proper model of tropospheric refraction. However, the uncertainties of the uplift rate are mostly larger than $5 \mathrm{~mm} / \mathrm{yr}$, and are larger than the uplift rates themselves at some sites in Tibet Plateau. It is important to survey continuously for a longer time and to survey 


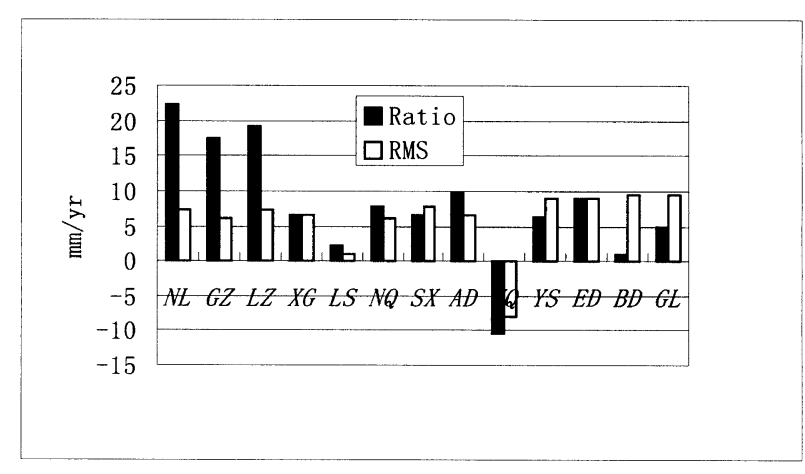

Fig. 3. Vertical velocity of GPS monitoring stations in Tibet Plateau (97-95), here NL, GZ, LZ and XG are deployed in the Southern Tibet.

repeated in a longer interval. Wenquan's uplift rate of about $-10.4 \pm 7.9 \mathrm{~mm} / \mathrm{yr}$ is difficult in interpreting. It seems much more likely that the site at Wenquan is unstable, or that it is affected by localized subsidence due to groundwater withdrawal, or that there was a blunder in one of the antenna height measurements.

More repeat GPS surveys in Tibet (including the Southern Tibet) and more monitoring sites are especially desirable to determine the mechanics of the uplift.

Acknowledgments. We thank Dr. Kosuke Heki, Dr. Jeff Freymueller and Dr. Makoto OMURA for their comments improving the manuscript greatly. This research was funded by National Nature Science Foundation of China grant 49234070, 49974001 and 49904001.

\section{References}

Chen, J. Y. and J. Zhang, On the crustal movement in Qumolongma feng and its adjacent area, ACTA Geophysica Sinica, 39, 67-78, 1996.

Herring, T. A., GLOBK: Global kalman filter VLBI and GPS analysis program, version 4.0, Mass. Inst. Technol., Cambridge, 1995.

Jackson, M. and R. Bilham, 1991-1992 GPS Measurements across the Nepal Himalaya, Geophys. Res. Lett., 21, 1169-1172, 1994a.

Jackson, M. and R. Bilham, Constraints on Himalayan deformation inferred from vertical velocity fields in Nepal and Tibet, J. Geophys. Res., 99(b7), 13897-13912, 1994b.

Jiang, F. Z., C. J. Zhang, Z. H. Ni, and Y. P. Liu, Isostatic field Nontidal gravity measurement in Qinghai-Xizang Plateau, ACTA Geophysica Sinica, 32, 465-469, 1989.

King, R. W. and Y. Bock, Documentation for the MIT GPS analysis software: GAMIT, version 9.3, Mass. Inst. Technol., Cambridge, 1995.

Ma, X. Y, Lithospheric dynamics atlas of China, China Cartographic Publishing House, Beijing China, 18, 1989.

Ma, Z. J., J. S. Zhang, and Y. P. Wang, The 3-d deformational movement episodes and neotectonic domains in the Qinghai-Tibet Plateau, ACTA Geologica Sinica, 72(3), 211-227, 1998.

Wang, W. Y. and Z. Q. Yang, Application of the GPS technology in the survey of plate tectonic motion and vertical crustal displacement in the Himalayan area, J. Xi'an coll. Geol., 15, 1-8, 1993.

Zhang, C. J., Study on the Qinghai-Xizang crust and its movements via the temporal and spatial gravity distribution, Seismology and Geology, 18(3), 237-244, 1996.

Zhang, Q. S., The problem of uplift rate of the Tibetan Plateau, Chinese Science Bulletin, 529-531, 1991 (in Chinese).

Zhang, Z., The map of the recent vertical crustal deformation rate in China, Chinese National Report on Geodesy presented to the 19th general assembly of IUGG, Vancouver, 1987.

Zhong, D. Q. and L. Ding, Science in China (series D), vol. 26, 289-295, 1996.

C. Xu (e-mail: cjxu@hpb1.wtusm.edu.cn), J. Liu, C. Song, W. Jiang, and C. Shi 